\title{
Letter to the editor by Dobran Mauro, Paracino Riccardo, and lacoangeli Maurizio regarding "Neurosurgery during the COVID-19 pandemic: update from Lombardy, northern Italy." Zoia C, Bongetta D, Veiceschi P, Cenzato M, Di Meco F, Locatelli D, Boeris D, Fontanella MM. Acta Neurochir (Wien). 2020 Mar 28. doi: 10.1007/s00701-020-04305-w
}

\author{
Mauro Dobran $^{1} \cdot$ Riccardo Paracino $^{1} \cdot$ Maurizio lacoangeli $^{1}$ \\ Received: 6 April 2020 / Accepted: 7 April 2020 / Published online: 17 April 2020 \\ (C) Springer-Verlag GmbH Austria, part of Springer Nature 2020
}

Dear Editor, we read with great interest the article by Cesare Zoia, Daniele Bongetta, Pierlorenzo Veiceschi, Marco Cenzato, Francesco Di Meco, Davide Locatelli, Davide Boeris, and Marco M. Fontanella "Neurosurgery during the COVID-19 pandemic: update from Lombardy, northern Italy" [4]. This study provided important insights into the management of patients with the COVID-19 disease discovered in Wuhan [5] and the interpretation of these findings may be enhanced by the following considerations. In Italy since February 2020 spread a massive coronavirus disease (COVID-19) with a great number of infected patients and deaths. To contrast the infection spread on March 2020 in Italy was declared the lockdown and the neurosurgical activity of the Department of Neurosurgery AOU Ancona-Italy was centered on emergency and oncological pathology. In consideration that human coronaviruses could start from the respiratory tract and spread to the central nervous system through transneuronal and hematogenous routes as reported by Desforges M. et al. in 2014, we must assume that also the new COVID-19 might infect the central nervous system too $[1,2]$. In this light, all neurosurgical departments should perform an early diagnosis and a correct management of all suspect infected patients to prevent the diffusion of the infection itself to the neurosurgical area [3]. Firstly the general rule is

This article is part of the Topical Collection on Neurosurgery general

Mauro Dobran

dobran@libero.it

1 Department of Neurosurgery, Universita Politecnica delle Marche, Ancona, Italy that all patients transferred from one hospital to another undergo a swab test before the transfer. In nonhospitalized patients admitted to hospital for urgent surgery, a swab test is performed but, because of the long time for its result, when a surgical procedure is urgent a pulmonary CT scan is performed to search for a COVID-19 pneumonia. In fact in emergency surgery, a pulmonary CT scan is the only method for a fast potential diagnosis of COVID-19 pneumonia. In COVID19-positive patients, surgery is performed with adequate personnel protections and dedicate path in the postoperative period. In our hospital to concentrate resources on COVID-19 emergency, the non-urgent activities were suspended and each department provided some of its doctors and nurses to reinforce the COVID-19 staff. To face the danger of contagion even in our neurosurgical department, measures have been implemented such as the suspension of all scheduled surgical activity with the exception of class A for oncologic patients, maintenance of neurosurgical emergencies (cerebral hemorrhages, hydrocephalus, tumors with intracranial hypertension, spinal cord compression, and traumatic cranial and spinal), and the urgent neurosurgical visit or the scheduled ones within 10 days. Luckily during this lockdown the cranial and spinal traumatic pathology decreased dramatically allowing the medical staff to be more available for COVID-19 emergencies. Unexpectedly there was a drop in the request of surgical treatments also for pathologies unrelated to traumatology (Fig. 1). While the decline of traumatology is explained by the block of car traffic and work activities, the demand decrease for neurosurgical treatment in spinal degenerative pathology appears incomprehensible. A possible reason could be the widespread fear of the population to go to hospital seen as a dangerous place for a possible infection. Another potential reason may be 


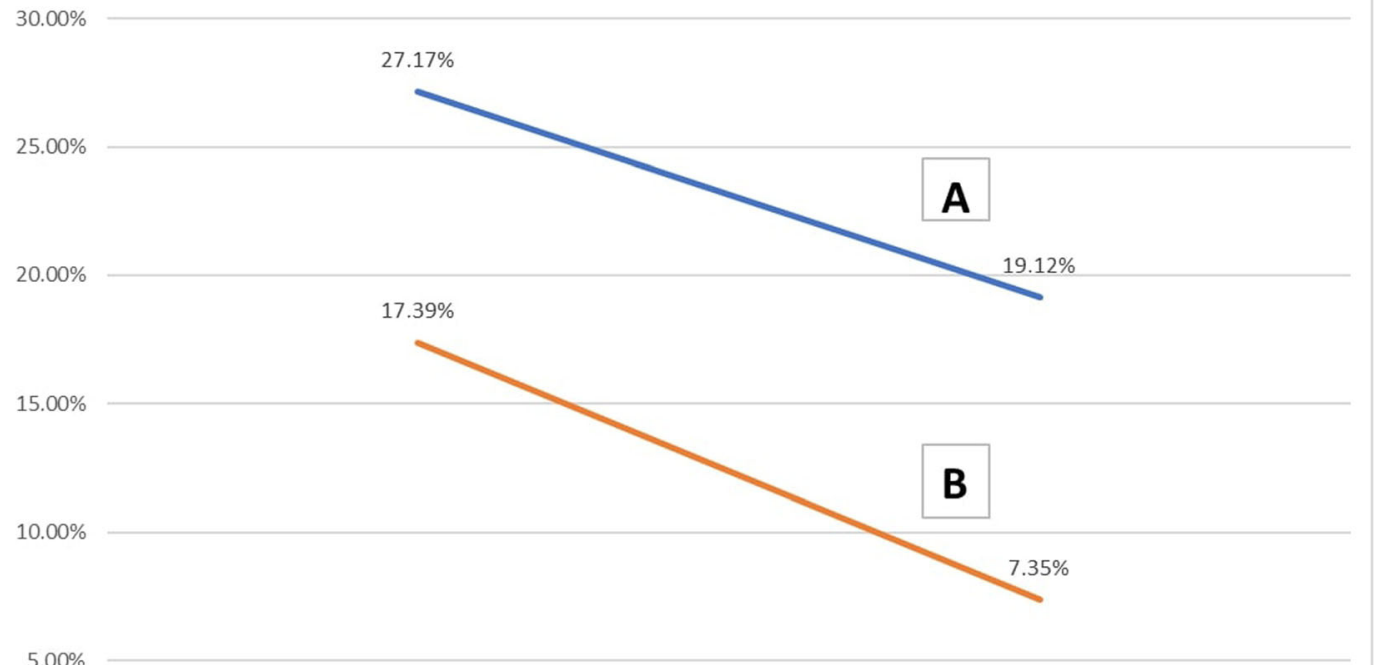

\begin{tabular}{|c|c|c|}
\cline { 2 - 3 } \multicolumn{1}{c|}{$0.00 \%$} & Feb-March 2019 & Feb-March 2020 \\
\cline { 2 - 3 } — spinal degenerative diseases [A] & $27.17 \%$ & $19.12 \%$ \\
\hline Spinal Traumatic injuries [B] & $17.39 \%$ & $7.35 \%$
\end{tabular}

Fig. 1 Drop in the request of surgical treatments also for pathologies unrelated to traumatology. (A) Spinal degenerative diseases. (B) Spinal Traumatic injuries

the patients' overestimation of their disability and pain with consequent neurosurgical overtreatment. We should investigate if since now we have been surgically treating too many patients who might have been healed by anti-inflammatory drugs and real long rest as is probably occurring now.

\section{Compliance with ethical standards}

Conflict of interest The authors declare that they have no conflict of interest.

\section{References}

1. Desforges M, Le Coupanec A, Brison E, Meessen-Pinard M, Talbot PJ (2014) Neuroinvasive and neurotropic human respiratory coronaviruses: potential neurovirulent agents in humans. Adv Exp Med Biol 807:75-96. https://doi.org/10.1007/978-81-322-1777-0 6 Review
2. Desforges M, Le Coupanec A, Stodola JK, Meessen-Pinard M, Talbot PJ (2014) Human coronaviruses: viral and cellular factors involved in neuroinvasiveness and neuropathogenesis. Virus Res 194:145-158. https://doi.org/10.1016/j.virusres.2014.09.011

3. Tan YT, Wang JW, Zhao K, Han L, Zhang HQ, Niu HQ, Shu K, Lei $\mathrm{T}$ (2020) Preliminary recommendations for surgical practice of neurosurgery department in the central epidemic area of 2019 coronavirus infection. Curr Med Sci. https://doi.org/10.1007/s11596-0202173-5

4. Zoia C, Bongetta D, Veiceschi P, Cenzato M, Di Meco F, Locatelli D, Boeris D, Fontanella MM (2020) Neurosurgery during the COVID19 pandemic: update from Lombardy, northern Italy. Acta Neurochir. https://doi.org/10.1007/s00701-020-04305-w

5. Zou J1, Yu H1, Song D1, Niu J1, Yang H1 (2020) Advice on standardized diagnosis and treatment for spinal diseases during the coronavirus disease 2019 pandemic. Asian Spine J. https://doi.org/10. 31616/asj.2020.0122

Publisher's note Springer Nature remains neutral with regard to jurisdictional claims in published maps and institutional affiliations. 